\title{
ESTABELECIMENTO DE BANCO FORRAGEIRO COM LEUCENA EM UNIDADE DE PRODUÇÃO FAMILIAR NO SUDESTE DO PARÁ
}

\author{
Pâmela Dias de Oliveira ${ }^{1}$; Rosana Quaresma Maneschy² Karolinny Carneiro Guerra Costa $^{3}$; \\ Tatiane Pereira Guimarães ${ }^{4}$; Ilmaione Keiza de Souza Oliveira ${ }^{5}$ \\ ${ }^{1}$ Discente de Agronomia, Faculdade de Ciências Agrárias de Marabá (FCAM), Universidade Federal do Pará (UFPA), \\ Bolsista FAPESPA, pamelannine@gmail.com \\ ${ }^{2}$ Prof. ${ }^{\text {, }}$, DSc. da FCAM, UFPA, romaneschy@ufpa.br \\ ${ }^{3}$ Discente de Agronomia, FCAM, UFPA, Bolsista PIBIC/UFPA, karolinnycg.guera@gmail.com \\ ${ }^{4}$ Discente de Agronomia, FCAM, UFPA, Bolsista FAPESPA, tatianepg.ufpa@ gmail.com \\ ${ }^{5}$ Discente de Agronomia, FCAM, UFPA, Bolsista PIBIC/PARD, ilmaionekeiza@ hotmail.com
}

RESUMO: Os impactos causados as florestas pelos sistemas pecuários comumente utilizados na região amazônica, tem provocado degradação dos solos e consequentemente das áreas de pastagem implantadas após o desflorestamento. A degradação das áreas de pastagens na região tem limitado a oferta de forragem durante o período seco do ano para os animais. No intuito de minimizar os impactos ambientais e aumentar a sustentabilidade desses sistemas de produção de agricultores familiares, esta pesquisa teve como objetivo implantar e acompanhar o estabelecimento de banco forrageiro com a leguminosa leucena (Leucaena leucocephala (Lam.)Wit.) Para isso foi implantada de forma participativa uma ação-teste em lote de agricultor familiar no município de São Domingos do Araguaia - PA, em março de 2009. A área da ação-teste foi de $400 \mathrm{~m}^{2}$ e o plantio da leucena foi realizado através de mudas, no espaçamento $1 \mathrm{~m}$ x $3 \mathrm{~m}$. Entre as fileiras de leucena foram plantadas quatro linhas de milheto (Pennisetum glaucum L.), com 0,70 m entre as fileiras e 0,20 m entre plantas. Foram realizadas avaliações da taxa de sobrevivência da leucena aos 30, 60, 90, 120, 150, 180, 210, 240, 270, 300 e 330 dias após o plantio; e de altura da planta (m) e diâmetro do coleto (mm) aos 90, 120, 150, 180, 210, 240, 270, 300 e 330 dias após o plantio. As mudas de leucena conseguiram se adaptar as condições em que foram estabelecidas, apresentando taxa de sobrevivência e crescimento satisfatórios.

PALAVRAS-CHAVE: Agricultura familiar, forragem, sistema silvipastoril, Leucena leucocephala.

\section{ESTABLECIMIENTO DE BANCO FORRAJERO CON LEUCAENA EN UNA UNIDAD DE PRODUCCIÓN FAMILIAR EN SURESTE DE PARÁ}

RESUMEN: Los impactos de los bosques para los sistemas ganaderos de uso común en la región del Amazonas ha provocado la degradación del suelo y por lo tanto las zonas de pastos plantados después de la deforestación. La degradación de los pastizales en la región, ha limitado la oferta de forraje durante la estación seca para los animales. Con el fin de minimizar los impactos ambientales y aumentar la sostenibilidad de los sistemas de producción de los agricultores, esta investigación tuvo como objetivo poner en práctica y seguimiento de la creación del banco con la leguminosa forrajera leucaena (Leucaena leucocephala (Lam) Wit.) Entonces se llevó a cabo en una acciónprueba participativa, en un lote de agricultores familiares en el municipio de São Domingos do Araguaia - PA, en marzo de 2009. El área de acción de la prueba fue de $400 \mathrm{~m}^{2}$ y la siembra de las plántulas de leucaena se llevó a cabo, una separación de $1 \mathrm{~m}$ x $3 \mathrm{~m}$. Entre las filas de leucaena se 
sembraron cuatro hileras de Pennisetum glaucum L., con $0,70 \mathrm{~m}$ entre hileras y $0,20 \mathrm{~m}$ entre plantas. Se evaluó la tasa de supervivencia de la leucaena a los 30, 60, 90, 120, 150, 180, 210, 240, 270, 300 y 330 días después de la plantación, y altura de planta $(\mathrm{m})$ y diámetro del tallo $(\mathrm{mm})$ a 90 , los días 120, 150, 180, 210, 240, 270, 300 y 330 después de la siembra. Las plántulas de leucaena tienen sabido adaptarse a las condiciones as cuales se establecieron, con la supervivencia y el crecimiento satisfactorios.

PALABRAS CLAVES: Agricultura familiar, sistema silvopastoril, Leucaena leucocephala.

\section{INTRODUÇÃO}

O processo de formação das atividades econômicas em áreas destinadas a reforma agrária geralmente passaram pelo extrativismo, num primeiro momento, seguido da retirada parcial e/ou total da vegetação natural e por último a instalação dos colonos nessas áreas (OLIVEIRA, 2008). No Sudeste Paraense até hoje as ocupações de terra se dão de forma intensa e sem planejamento adequado dos assentados.

O processo de derruba e queima, é o primeiro mecanismo adota pelos agricultores na intenção de obter, durante dois ou três anos, os nutrientes que precisam para as lavouras de subsistência (GUANZIROLI et al., 2001). Após alguns anos de instalação, a pecuarização dessas áreas é iminente, pois a mata que provia parte da subsistência da família (caça, coleta de frutos) e dinheiro com a venda de madeira, não existe mais ou se tornou insustentável.

Os impactos causados as florestas pelo novo sistema de produção vigente, baseado na pecuária extensiva, tem provocado degradação dos solos e conseqüentemente das áreas de pastagem, nutridas anteriormente, pela ciclagem de nutrientes decorrente do sistema solo-planta. Os altos níveis de degradação das áreas implantadas com pastagem, segundo Carneiro et al. (2006) tem limitado a oferta de alimentos suculentos e verdes durante o período seco.

A adoção de sistemas agroflorestais (SAF) tem sido indicada para a reabilitação de áreas degradação. Segundo Oliveira et al. (2003) os sistemas silvipastoris despontam como alternativa promissora por serem mais diversificados e potencialmente mais produtivos e sustentáveis que os sistemas pecuários tradicionais (gado/roça/capoeira).

Para Dubois et al. (1996) o uso de espécies forrageiras arbóreas ou arbustivas só é considerado alternativas viáveis para suplementação dos animais, quando reúnem determinadas qualidades como, folhas ricas em nutrientes, fácil digestão pelos animais, palatáveis, boa capacidade de regenerar sua folhagem depois de desfolhadas pelo gado ou podadas pelo homem e se constituir uma fonte 
de alimento para os animais, principalmente durante os últimos meses do verão, quando as gramíneas e leguminosas forrageiras herbáceas estão secas.

\section{A leucena (Leucaena leucocephala} (Lam) Wit.) é originária da América Central e se dispersou para outras partes do mundo devido à sua versatilidade de utilização (SOUZA et al., 2007), podendo ser empregada na arborização de pastagem, pastejo direto para os animais, forragem picada, banco de proteína (PAULINO, 2004), sendo este último de grande importância para áreas com atividades pecuárias.

No intuito de promover a sustentabilidade em lotes de agricultores familiares assentados na região sudeste do Pará, estabeleceu-se banco forrageiro com leucena objetivando acompanhar o seu desenvolvimento, durante a fase de estabelecimento, em ação teste realizada em lote de agricultor familiar.

\section{MATERIAL E MÉTODOS}

A pesquisa foi uma ação do projeto "Sistemas silvipastoris e agrossilvipastoris como alternativa para a sustentabilidade da pecuária na agricultura familiar da região de Marabá - PA" desenvolvido pela Universidade Federal do Pará - Campus de Marabá com apoio financeiro da FAPESPA.
A abordagem metodológica foi da pesquisaação e participativa através da construção de inovações em parcerias com agricultores (CHIA et al., 2006).

O Projeto de Assentamento (P.A.) onde a pesquisa se desenvolve é o Belo Horizonte I, situado à altura do km 30 da BR153, no município de São Domingos do Araguaia, na microrregião de Marabá, composto por aproximadamente 40 famílias.

Nesse contexto de pesquisa participativa foi escolhido pelos agricultores o uso de gramíneas e leguminosas forrageiras de alta qualidade para serem implantadas ações testes em diferentes lotes de agricultores. Dentre as espécies escolhidas ressalta-se o milheto (Pennisetum glaucum L.) e a leucena (Leucaena leucocephala Lam.) Wit. que foram escolhidas por uma família para implantação de ação teste silvipastoril.

O clima no local segundo a classificação de Köppen é Am no limite de transição para Aw com temperatura média anual de $26,3^{\circ} \mathrm{C}$, caracterizado por um, período menos chuvoso entre os meses de maio e outubro e um período mais chuvoso entre os meses de novembro a abril. Solo podzólico vermelho amarelo com textura argilo-arenosa (NAVEGANTES-ALVES, 2009). 
A área escolhida pela família, segundo o histórico relatado, tinha como vegetação dominante floresta primária, que foi derrubada para a formação de pastagem a cerca de 20 anos - inicialmente com o quicuio (Brachiaria humidicola (Rendle) Schweick) que há 10 anos foi substituído pelo capim estrela (Cynodon sp.). Para o preparo da área o agricultor utilizou apenas o herbicida glifosato (mata pasto) oito dias antes do plantio para facilitar a limpeza manual, não foi realizado nenhum tipo de adubação no local.

A ação teste foi implantada em março de 2009, em uma área de $400 \mathrm{~m}^{2}$. As mudas de leucena foram plantadas em fileiras intercaladas a cada quatro linhas de milheto, o espaçamento entre as fileiras de leucena e o milheto foi de $1 \mathrm{~m}$, e entre as plantas de leucena na linha foi de $3 \mathrm{~m}$. O espaçamento utilizado para o milheto foi de 0,70 entre as linhas e 0,20 m entre plantas. Foram realizadas entrevistas não diretivas com o agricultor para que o mesmo relatasse quais tratos culturais estava realizando na ação teste. Nessa ocasião também foram avaliadas as plantas de leucena da seguinte forma: taxa de sobrevivência aos 30,60, 90, 120, 150, 180, 210, 240, 270, 300 e 330 dias após o plantio, e de altura total da planta (m); e diâmetro do coleto $(\mathrm{cm})$ aos 90, 120, 150, 180, 210, 240, 270, 300 e 330 dias após o plantio.

As avaliações foram realizadas em todas as plantas da ação teste, desconsiderando a bordadura. Foram testadas equações de regressão para estimar os padrões de crescimento avaliados em relação à idade do plantio. A acurácia dos modelos de regressão foi avaliada por meio do teste $\mathrm{F}$ ao nível de 5\%. Também foram realizadas entrevistas não diretivas com a família para o relato dos tratos culturais efetuados na manutenção da ação-teste.

Tabela 1 - Características físicas e químicas do solo de ação-teste silvipastoril com leucena, na camada de 0-20 cm, em São Domingos do Araguaia, Pará.

\begin{tabular}{|c|c|c|c|c|c|c|c|c|c|c|c|c|c|c|}
\hline $\begin{array}{l}\text { Areia } \\
\text { grossa }\end{array}$ & $\begin{array}{l}\text { Areia } \\
\text { fina }\end{array}$ & Silte & $\begin{array}{c}\text { Argila } \\
\text { total }\end{array}$ & $\begin{array}{c}\mathrm{pH} \\
\text { (água) }\end{array}$ & P & $\mathrm{ng} \mathrm{d}$ & $\mathrm{Na}$ & $\mathrm{Ca}$ & $\mathrm{Ca}+\mathrm{Mg}$ & $\mathrm{Al}$ & $\mathrm{Cu}$ & -----mg & Kg---- & $\mathrm{Zn}$ \\
\hline 204 & 398 & 254 & 145 & 5,5 & 3 & 119 & 39 & 1,6 & 2,8 & 1,7 & 3,7 & 204,9 & 249,3 & 5,4 \\
\hline
\end{tabular}




\section{RESULTADOS E DISCUSSÃO}

Foi realizada a rega das plantas sempre que necessário e a capina manual para evitar a competição entre a leucena e as espécies invasoras. $\mathrm{O}$ agricultor relatou que apesar da ocorrência de formiga (Atta sp.) na área da ação-teste as mesmas não têm causado injúrias nas plantas, que segundo Peres Filho et al. (2002) é suscetível a este tipo de ataque. Barcellos et al. (2001) relataram que as formigas são uma praga importante durante toda a vida dessa leguminosa, sob risco de diminuição acentuada da população de plantas e redução na oferta de forragem aos animais.

O desenvolvimento da leucena foi considerado satisfatório entre os 30 e 330 dias após o plantio (Tabela 2), na qual sua taxa de sobrevivência permaneceu em 91,67\%. Esses resultados corroboram com Shelton (2001), que afirma que a leucena é resistente a seca e de fácil adaptação a solos de baixa fertilidade como o da área onde a ação-teste foi implantada. Medrado e Fowler (1998), também reportaram resultados semelhantes sem a realização da inoculação com fungos micorrízicos arbusculares.

As relações dos parâmetros de crescimento nos períodos avaliados foram consideradas significativas $(\mathrm{p} \geq 0,05)$ e ajustadas retas de regressão linear simples (Figura 1). O desenvolvimento das mudas no campo em relação à altura e diâmetro do coleto também foi considerado adequado, pois apresentou resultados semelhantes aos de Lins et al. (2007) em condições de estresse para as plantas.

Nessa pesquisa verificou-se que as plantas só apresentaram altura viável para corte 12 meses após o plantio. Mas segundo Primavesi et al. (1996) cultivares de leucena mesmo em condições adversas podem apresentar, possibilidade de primeiro corte aos nove meses após o plantio, inclusive com boa capacidade de rebrota.

O nível de crescimento das plantas de leucena, entre os períodos de 120 a 210, comparados aos meses seguintes (clima favorável), se mantiveram adequados mesmo em condições de estresse, fato já mencionado por Souza e Espíndula (2000).

Lins et al. (2007) citam que graças ao sistema radicular profundo que as espécies de leguminosas arbóreas e arbustivas possuem, as tornam mais resistentes à seca que leguminosas herbácias, contribuindo na retenção de água e sais minerais essenciais nesta época do ano.

A observação feita por Gama (2008) tornou-se relevante ao resultado satisfatório da taxa de sobrevivência das mudas de leucena, pois o mesmo constatou que plantas da família Leguminosae, como leucena, realizam um sistema simbiótico eficiente com 
bactérias fixadoras de nitrogênio, que chegam a incorporar cerca de $500 \mathrm{~kg} \mathrm{ha}^{-1} \mathrm{ano}^{-1} \mathrm{de}$ nitrogênio $(\mathrm{N})$ ao solo, o que favorece o estabelecimento e crescimento das plantas.

Tabela 2 - Altura total (AT) e diâmetro do coleto (Dcol), da leucena (Leucaena leucocephala Lam. De Wit.), em ação-teste silvipastoril em unidade de produção familiar no P. A. Belo Horizonte I, São Domingos do Araguaia, Pará.

\begin{tabular}{lccccccccc}
\hline \multirow{2}{*}{ Parâmetro Período de Avaliação (dias) } \\
\cline { 2 - 10 } & 90 & 120 & 150 & 180 & 210 & 240 & 270 & 300 & 330 \\
\hline AT $(\mathrm{m})$ & 0,48 & 0,65 & 0,73 & 0,77 & 0,82 & 1,17 & 1,29 & 1,35 & 1,46 \\
& $( \pm 0,14)$ & $( \pm 0,14)$ & $( \pm 0,13)$ & $( \pm 0,15)$ & $( \pm 0,15)$ & $( \pm 0,11)$ & $( \pm 0,12)$ & $( \pm 0,12)$ & $( \pm 0,06)$ \\
DCol & 3,92 & 4,64 & 5,94 & 6,37 & 6,82 & 7,22 & 7,93 & 8,46 & 9,02 \\
$(\mathrm{~mm})$ & $( \pm 1,34)$ & $( \pm 1,59)$ & $( \pm 2,16)$ & $( \pm 2,30)$ & $( \pm 2,42)$ & $( \pm 2,55)$ & $( \pm 2,76)$ & $( \pm 2,90)$ & $( \pm 3,04)$ \\
\hline
\end{tabular}

Onde: Os valores entre parênteses representam o desvio padrão da média.
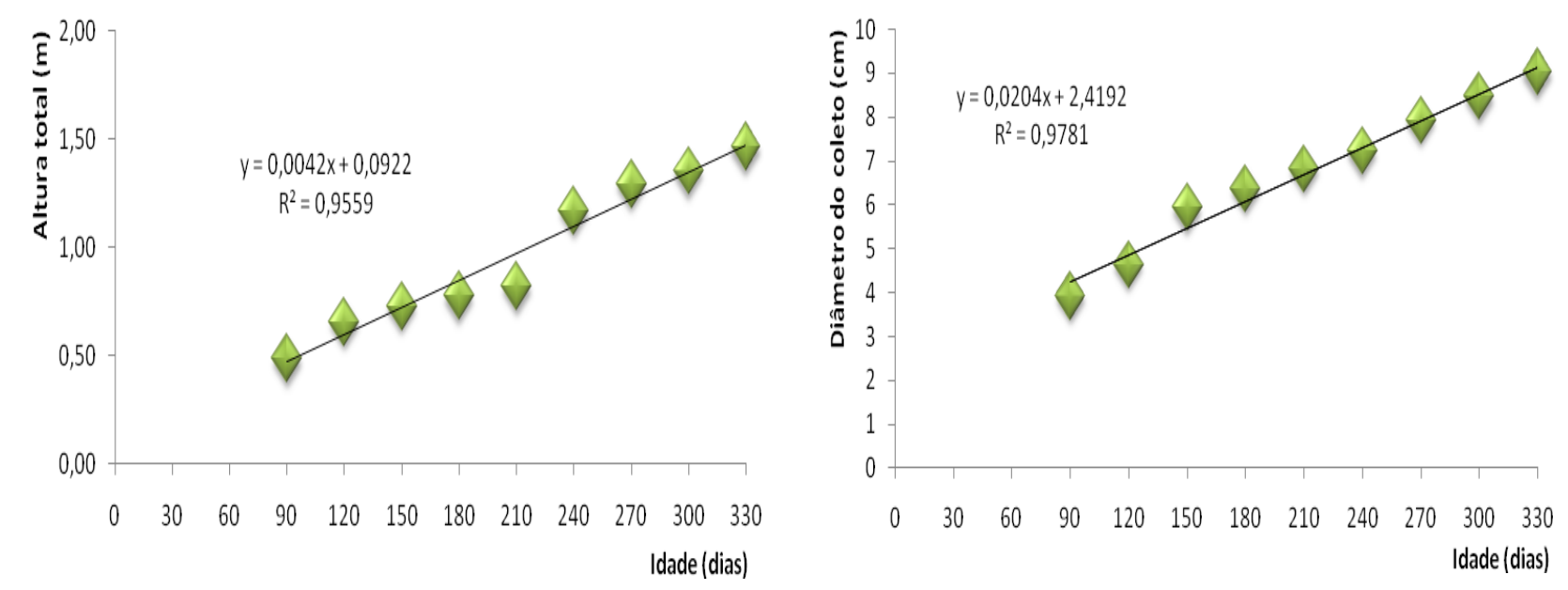

Figura 1 - Relações dos parâmetros de crescimento altura total e diâmetro do coleto com a idade de plantio das espécies leucena (Leucaena leucocephala Lam.), implantadas em ação-teste silvipastoris de unidade de produção familiar no P. A. Belo Horizonte I, São Domingos do Araguaia, Pará.

\section{CONCLUSÕES}

As mudas de leucena conseguiram se adaptar as condições em que foram estabelecidas no lote do agricultor, apresentando taxa de sobrevivência e crescimento satisfatórios mesmo sob 
condições de estresse. Ao final do primeiro ano após o plantio as plantas apresentaram altura viável para corte.

\section{REFERÊNCIAS}

CHIA, E.; DUGUÉ, P.; SAKHO-JIMBIRA, $S$. Les exploitations agricoles familiales sont-elles des institutions? In: Agricultures, v. 15, n. 6, p. 498-505, 2006.

DRUMOND, M. A. Leucena: Uma arbórea de uso múltiplo, para a região semi-árida do Nordeste Brasileiro. In: SIMPÓSIO BRASILEIRO DE CAPTAÇÃO DE ÁGUA DE CHUVA NO SEMI-ÁRIDO. 3, 2001, Campina Grande. Anais. Campina Grande: Johan Gnadlinger, 2001. v.1. CD-ROM.

DUBOIS, J. C. L.; VIANA, V. M.; ANDERSON, A. B. Manual Agroflorestal para a Amazônia. Rio de Janeiro: REBRAF, 1996. 228 p.

GAMA, T. C. M. Avaliação de leguminosas Forrageiras lenhosas como banco de proteínas para suplementação de ruminantes. Campo Grande, MS: CIP, 2008.

GUANZIROLI, C. et al. Agricultura Familiar e Reforma Agrária no Século XXI. Rio de Janeiro: Garamond, 2001. 288 p.

NAVEGANTES-ALVES, L. Gestion des pâturages en Amazonie Orientale: les décisions des pratiques. Montpellier, França: SUPAGRO - SIBAGHE, 2009 (Tese de doutorado em andamento).

OLIVEIRA, M. N. D. Análise dos principais fatores de erosão dos solos no projeto de assentamento Lajedo. Trabalho de conclusão de curso (graduação) da Universidade federal do Pará, Marabá, PA: Colegiado de Agronomia, 2008.
OLIVEIRA, T. K.; FURTADO, S. C.; ANDRADE, C. M. S.; FRANK, I. L. Sugestões para implantação de Sistemas Silvipastoris. Rio Branco, AC: EMBRAPA ACRE, 2003. 28 p.

PRIMAVESI, A. C.; PRIMAVESI, O.; GODOY, R. Avaliação de genótipos de leucaena Spp nas condições edafoclimáticas de São Carlos, SP. São Carlos: EMBRAPACPPSE, 1996. 5p. (EMBRAPA-CPPSE. (Comunicado Técnico, 14).

RUSSO, R.; PÁDUA, C. V. Avaliação de Aspectos da Sustentabilidade Ambiental deSistemas Agroflorestais. In: III Congresso Brasileiro Sobre Sistemas Agroflorestais, 2000, Manaus, Anais... Manaus: EMBRAPACPAA, 2001. 4p. (EMBRAPA-CPAA. Documentos, 17).

SEIFFERT, N. F. Low performance of Leucaena Perutype on Central Brasil Oxisols. Hawaii. Leucaena Research Reports, v. 3, p. 7-8, 1982.

SHELTON, H. M. Potenciais e limitações de Leucaena spp. para uso em sistemas silvipastoris. In: CARVALHO, M. M.; ALVIM, M. J.; CARNEIRO, J. C. (Ed.). Sistemas agroflorestais pecuários: opções de sustentabilidade para áreas tropicais e subtropicais. Juiz de Fora: Embrapa Gado de Leite, Brasília: FAO, 2001. p. 379 - 398.

\section{AGRADECIMENTOS}

O presente trabalho foi realizado com o apoio da PROPESP/UFPA através do PIBIC e da Fundação de Amparo a Pesquisa do Estado do Pará - FAPESPA. 